Article

\title{
A Cell-Free SDKP-Conjugated Self-Assembling Peptide Hydrogel Sufficient for Improvement of Myocardial Infarction
}

Saman Firoozi ${ }^{1}$ Sara Pahlavan ${ }^{2}$ Mohammad-Hossein Ghanian ${ }^{3}$ (D) Shahram Rabbani ${ }^{4}$ Shima Tavakol ${ }^{5}$, Maryam Barekat ${ }^{6}$, Saeed Yakhkeshi ${ }^{2}$, Elena Mahmoudi ${ }^{7}$, Mansoureh Soleymani ${ }^{5, *}$ and Hossein Baharvand ${ }^{2,8, *(D)}$

1 Department of Tissue Engineering and Regenerative Medicine, Faculty of Advanced Technologies in Medicine, Iran University of Medical Sciences, Tehran 1449614535, Iran; saman.nano1989@gmail.com

2 Department of Stem Cells and Developmental Biology, Cell Science Research Center, Royan Institute for Stem Cell Biology and Technology, ACECR, Tehran 1665659911, Iran; sarah.pahlevan2007@gmail.com (S.P.); saeedyakhkeshi@gmail.com (S.Y.)

3 Department of Cell Engineering, Cell Science Research Center, Royan Institute for Stem Cell Biology and Technology, ACECR, Tehran 1665659911, Iran; biomaterialist@gmail.com

4 Research Center for Advanced Technologies in Cardiovascular Medicine, Tehran Heart Center, Tehran University of Medical Sciences, Tehran 1416753955, Iran; sh-rabbani@tums.ac.ir

5 Cellular and Molecular Research Center, Iran University of Medical Sciences, Tehran 1449614535, Iran; shima.tavakol@yahoo.com

6 Department of Regenerative Medicine, Cell Science Research Center, Royan Institute for Stem Cell Biology and Technology, ACECR, Tehran 1665659911, Iran; barekat1001@yahoo.com,

7 Massachusetts General Hospital, Harvard Medical School, Boston, MA 02114, USA; elena.mahmoudi@gmail.com

8 Department of Developmental Biology, University of Science and Culture, ACECR, Tehran 1461968151, Iran

* Correspondence: mansourehsoleimani@gmail.com (M.S.); Baharvand@Royaninstitute.org (H.B.); Tel.: +98-21-8670-4714 (M.S.); +98-21-22306485 (H.B.); Fax: +98-21-8862-2533 (M.S.); +98-21-23562507 (H.B.)

Received: 4 December 2019; Accepted: 25 January 2020; Published: 30 January 2020

check for updates

\begin{abstract}
Biomaterials in conjunction with stem cell therapy have recently attracted attention as a new therapeutic approach for myocardial infarction (MI), with the aim to solve the delivery challenges that exist with transplanted cells. Self-assembling peptide (SAP) hydrogels comprise a promising class of synthetic biomaterials with cardiac-compatible properties such as mild gelation, injectability, rehealing ability, and potential for sequence modification. Herein, we developed an SAP hydrogel composed of a self-assembling gel-forming core sequence (RADA) modified with SDKP motif with pro-angiogenic and anti-fibrotic activity to be used as a cardioprotective scaffold. The RADA-SDKP hydrogel was intramyocardially injected into the infarct border zone of a rat model of MI induced by left anterior descending artery (LAD) ligation as a cell-free or a cell-delivering scaffold for bone marrow mesenchymal stem cells (BM-MSCs). The left ventricular ejection fraction (LVEF) was markedly improved after transplantation of either free hydrogel or cell-laden hydrogel. This cardiac functional repair coincided very well with substantially lower fibrotic tissue formation, expanded microvasculature, and lower inflammatory response in the infarct area. Interestingly, BM-MSCs alone or in combination with hydrogel could not surpass the cardiac repair effects of the SDKP-modified SAP hydrogel. Taken together, we suggest that the RADA-SDKP hydrogel can be a promising cell-free construct that has the capability for functional restoration in the instances of acute myocardial infarction (AMI) that might minimize the safety concerns of cardiac cell therapy and facilitate clinical extrapolation.
\end{abstract}

Keywords: mesenchymal stem cells; cardiac cell therapy; self-assembling peptidehydrogel; myocardial infarction 


\section{Introduction}

Myocardial infarction (MI) is the most prevalent among cardiac disorders and has high morbidity and mortality rates [1]. Blockage of the coronary artery results in MI that is characterized by local ischemia and apoptosis of conforming cardiac cells that include cardiac progenitor cells (CPCs), cardiomyocytes, smooth muscle cells, and endothelial cells [2]. Inflammatory cells migrate to the infarcted area and produce large amounts of reactive oxygen species (ROS) [3]. Thus, the cardiac environment converts to an inflamed area with low oxygen levels, high amounts of ROS, large numbers of apoptotic cells, and disintegrated extracellular matrix (ECM). Once inflammation is reduced, cardiac tissue is replaced by scar tissue, which is accompanied by dilation of the left ventricle (LV) $[4,5]$. Conventional therapeutic approaches for MI have been developed based on revascularization by different means such as balloon angioplasty or coronary artery bypass grafting [6]. Although mostly successful, these revascularization methods could not fully inhibit ventricular remodeling due to hypoxia in the infarct area. One major challenge is restoration or replacement of damaged myocardium. Injured myocardium leads to development of dilated ventricles and consequent heart failure [7]. Cardiac cell therapy is a promising approach for myocardial regeneration [8]. Various cell sources have been transplanted into the infarcted area to restore cardiac function via direct myogenesis such as CPCs [9] and mesenchymal stem cells (MSCs) [10] or their paracrine effects on resident cells such as CPCs [9], MSCs [10], endothelial progenitor cells (EPCs) [11], and hematopoietic stem cells (HSCs) [11]. In particular, several clinical trials have been designed or conducted based on the promising results of MSC therapy for MI (clinicaltrials.gov identifier: NCT03798353, NCT02323477, NCT01392105, NCT00114452, NCT01291329). However, cardiac cell therapy has shown partial success, which is likely due to low engraftment of the transplanted cells $[12,13]$. Both viability and retention of the transplanted cells could be hampered by insufficient nutrition caused by lack of vasculature, inflammatory conditions, and remodeled ECM in the fibrotic area [14].

To circumvent the challenges of cell therapy, tissue engineering has emerged as an option to induce cardiac repair using biomaterial scaffolds as cell delivery vehicles or cell-free therapeutic agents. With scaffold-mediated cell delivery, a higher rate of cell retention and viability could be achieved due to greater cell-ECM interactions at the transplantation site [15]. More importantly, the biomaterial scaffolds could work alone as a cell-free approach to induce cardiac repair by providing mechanical support for the dilated ventricle and/or release of bioactive agents to induce angiogenesis, cell recruitment, and immunomodulatory effects [16]. Hydrogels are a subgroup of biomaterials that have a high water content and tunable crosslink density, which allows for controlled delivery of cells and other bioactive agents [16-18]. Hydrogel-based scaffolds can be injected into the infarcted site via minimally invasive surgical methods. Thus, they are of special interest as a therapeutic approach to prevent adverse LV remodeling [19]. A vast pool of materials have been assessed for this purpose, and range from natural polymers such as myocardial ECM [20], hyaluronate [21], collagen [22], fibrin [23], and alginate [24] to synthetic polymers such as ureido-pyrimidinone-modified poly(ethylene glycol) [25] and poly(N-isopropylacrylamide) [26]. Despite a wide range of preclinical studies with promising outcomes, their translation to the clinic has been limited to a very few hydrogels that have reached final phases of clinical trials. These include myocardial ECM hydrogel (clinicaltrials.gov identifier NCT02305602) and alginate hydrogel (NCT3082508 and NCT01311791). Reasons for this unsuccessful translation include safety concerns and batch-to-batch variations of the natural polymers, whereas the alternative synthetic polymers usually suffer from poor bioactivity [27]. Self-assembling peptides (SAPs) are a class of synthetic polymers that can be tailored to form bioactive hydrogels through biocompatible supramolecular interactions. SAPs are composed of a series of hydrophobic and hydrophilic amino acids that can be induced for structural organization by the addition of multivalent ions [28]. SAP hydrogels have been used to treat MI in preclinical studies with promising outcomes [29-31]. In one study, an SAP hydrogel with heparin-binding peptide motif that was amenable to vascular endothelial growth factor (VEGF) and bFGF binding was injected at the site of injury in an acute MI model. The results showed improved hemodynamic functions [32]. Recently, an MSC-laden SAP hydrogel was used in the form 
of epicardial coating at the site of infarction and resulted in enhanced left ventricular ejection fraction (LVEF\%) after four weeks [15].

The moldable synthesis of SAPs could allow for incorporation of bioactive peptide motifs to the main hydrogel-forming oligopeptide, which is the core motif [28]. Herein, we conjugated a bioactive motif (SDKP) with angiogenic, anti-inflammatory, and anti-fibrotic functions [33-37] to a common core motif composed of four RADA sequences whose final product was an injectable supramolecular hydrogel ((RADA)4-SDKP) The angiogenic potential of the (RADA)4-SDKP hydrogel was shown by in vitro and ex ovo experiments. We applied the (RADA)4-SDKP hydrogel in a rat model of MI to alleviate the inflammatory conditions and provide a permissive environment for revascularization of the damaged myocardium. These features were confirmed by the results of in vivo analysis. Interestingly, the cell-free hydrogel was highly cardioprotective, improved functional parameters and reduced scar formation at the infarct area, and was comparable with the MSC-laden hydrogel.

\section{Materials and Methods}

\subsection{Preparation of the (RADA)4-SDKP Hydrogel}

RADA16-I was selected as the core due to its well-known ability for mild gelation via self-assembly [15], GG was employed as spacer, and this construct was decorated with SDKP motif due to its biological functions. RADA16-I was selected based on the design of a commercial product named PuraMatrixTM (PuraMatrixTM, BD, Erembodegem, Belgium) [38,39] that has also been used for cardiac repair [2]. (RADA)4-SDKP peptide ( $\mathrm{N}$-terminus $\rightarrow$ C-terminus: Ac-RADARADARADARADAGGSDKP-NH2) was custom synthesized by DG Peptides Co., Ltd. (Hangzhou, China). The (RADA)4-SDKP powder was dissolved in deionized water (DEPS) at a concentration of $0.5 \%$. Then, it was sonicated for $30 \mathrm{~min}$ before the experiments. To prepare the hydrogel, we mixed the (RADA)4-SDKP solution with an equal volume of phosphate-buffered saline (PBS) to form the gel with a final concentration of $0.25 \%$ after $1 \mathrm{~min}$. The $0.25 \%$ concentration of SAP hydrogel has been used before [40] and proposed by in vivo protocols of PuraMatrix ${ }^{\mathrm{TM}}$, which is composed of (RADA)4 hydrogel.

\subsection{Characterization of the (RADA)4-SDKP Hydrogel}

The viscoelasticity of SAP hydrogel was analyzed using a stress-controlled rheometer (Paar Physica, MCR300 SN599139, EU). We injected $500 \mu \mathrm{L}$ of the hydrogel into the lower plate $(10 \mathrm{~mm}$ diameter and $1 \mathrm{~mm}$ thickness). The upper plate (20 mm diameter) was lowered until it contacted the gel surface, and the examination was done by oscillatory frequency sweeps (0.1-600 s ${ }^{-1}, 0.5 \%$ strain). The microstructure of the SAP hydrogel was assessed by a field emission scanning electron microscope (FESEM) (MIRA3\Tescan, Brno, Czech Republic). For this purpose, $500 \mu \mathrm{l}$ of the hydrogel were frozen at $-20^{\circ} \mathrm{C}$ and lyophilized for $48 \mathrm{~h}$. The obtained sponge was sputter coated with gold and observed using FESEM.

\subsection{Cytocompatibility of the (RADA)4-SDKP Hydrogel}

\subsubsection{Isolation of Neonatal Mouse Cardiomyocytes (NMCMs)}

NMCMs were isolated from one-day-old pups according to a protocol described previously [41]. All animal studies were performed in accordance with guidelines approved by the Ethics Committee of Royan Institute (Tehran, Iran IR.ACECR.ROYAN.REC.1398.192). Briefly, the hearts were excised and rapidly rinsed in cold Hank's balanced salt solution (HBSS, Gibco USA). All non-cardiac tissues and the atria were carefully dissociated from the ventricles. Then, the ventricles were further rinsed in cold HBSS to remove any remaining blood and then they were minced into small pieces. Next, the pieces were treated with HBSS/trypsin $(0.5 \mathrm{mg} / \mathrm{mL})$ overnight at $4{ }^{\circ} \mathrm{C}$ on an orbital shaker at $80 \mathrm{rpm}$. After the predigestion step, warm culture medium that consisted of $75 \%$ Dulbecco's Modified Eagle Medium (DMEM, Gibco), 25\% Media 199 (M-199, Gibco), 1\% penicillin/streptomycin (pen/strep, 
Gibco), 1\% L-glutamine (Gibco), and 1\% 4-(2-hydroxyethyl)-1-piperazine ethanesulfonic acid (HEPES, Gibco) was added to the trypsinized heart tissues. After discarding the predigestion media, the heart tissue was subjected to serial digestions with an HBSS/collagenase II $(0.8 \mathrm{mg} / \mathrm{mL})$ solution on an orbital shaker at $37^{\circ} \mathrm{C}$. Following the digestion steps, we collected the supernatants, centrifuged them at $800 \mathrm{rpm}$ for $5 \mathrm{~min}$ at room temperature, and resuspended the cell pellet in culture media composed of DMEM, M-199, 1\% pen/strep, 1\% L-glutamine, 1\% HEPES, 20\% horse serum (Gibco), and 10\% fetal bovine serum (FBS, Invitrogen, Carlsbad, CA, USA). The cell suspension was preplated on $0.1 \%$ gelatin-coated T-75 flasks for $1 \mathrm{~h}$ at $37{ }^{\circ} \mathrm{C}$ and $5 \% \mathrm{CO}_{2}$ to remove the isolated cardiac fibroblasts and obtain a homogeneous population of cardiomyocytes. Finally, the preplate supernatant was collected and centrifuged, and the pellet of NMCMs was resuspended in culture media.

\subsubsection{MTS Assay}

The impact of (RADA)4-SDKP hydrogel encapsulation on metabolic activity and proliferation of NMCMs was evaluated by MTS assay. Briefly, $1 \times 10^{4}$ NMCMs were cultured alone (control) or encapsulated in the (RADA)4-SDKP hydrogel at a final concentration of $0.25 \% v / w$ into each well of a 96-well plate that contained culture media for 24,48 , and $72 \mathrm{~h}$ at $37^{\circ} \mathrm{C}$ and $5 \% \mathrm{CO}_{2}(n=4)$. After each incubation period, the cell-seeded plates or cell-laden gels $(n=4)$ were incubated for $4 \mathrm{~h}$ with MTS reagent (Promega, USA) and the supernatant was analyzed for absorbance at $490 \mathrm{~nm}$.

\subsection{Angiogenic Potential of (RADA)4-SDKP Hydrogel In Vitro and Ex Ovo}

\subsubsection{In Vitro Vascular Endothelial Growth Factor (VEGF) Secretion Assay}

VEGF release by human umbilical vein endothelial cells (HUVECs) was evaluated in two forms of the cultured cells alone or encapsulated within (RADA)4-SDKP. For this purpose, HUVECs were isolated from aseptic human umbilical cords that were received from Arash Hospital (Tehran, Iran) after obtaining written consent from volunteer couples, as previously described [42]. The HUVECs were cultured in EGM-2 supplemented with 10\% FBS (10,270, Gibco). All in vitro experiments were performed using passages 3-6 HUVECs, and the cells were incubated at $5 \% \mathrm{CO}_{2}$ and $37^{\circ} \mathrm{C}$ and tested regularly for mycoplasma contamination by our laboratory. Then, $1 \times 10^{4}$ HUVECs were cultured alone (control) or encapsulated into the hydrogel at a final concentration of $0.25 \% \mathrm{v} / \mathrm{w}$ onto each well of a 48-well plate that contained the aforementioned medium for 24 or $124 \mathrm{~h}(n=3)$. Next, conditioned media from the cultured cells were collected and assessed by enzyme-linked immunosorbent assay (ELISA) using a Human VEGF DuoSet ELISA DY293B-05 kit (R\&D Systems, Minneapolis, Minnesota, USA) according to the manufacturer's instructions.

\subsubsection{Chicken Chorioallantoic Membrane (CAM) Assay}

Fertilized eggs from Hy-line W-36 hens were obtained from a commercial farm. The eggs were cracked under a sterile laminar flow hood and the contents were transferred to a Petri dish. Each embryo with the yolk was transferred to a surrogate shell, which was 3-4 g heavier than the egg shell, sealed with plastic wrap, and allowed to incubate in a forced-air incubator for $60 \mathrm{~h}$ at $37^{\circ} \mathrm{C}$ and $60 \%$ humidity. The embryonic day (ED) when the eggs were placed in the incubator was considered to be embryonic day 0 (ED0). On ED2.5, the yolk-embedded embryo was transferred to a second surrogate shell, which was 35 to $40 \mathrm{~g}$ heavier than the egg shell, sealed with plastic wrap, and allowed to incubate for another 5 days. Dead or infected embryos were removed daily to avoid further contamination. The chorioallantoic membrane (CAM) angiogenesis assay was performed as previously described [43]. Briefly, O-ring paper filters that contained PBS (vehicle) or (RADA)4-SDKP hydrogel at a final concentration of $0.25 \% v / w$ (gel) were deposited on the intact CAMs at ED9, at a location distal from the embryo and proximal to the major blood vessels. The embryos were maintained in the incubator for $72 \mathrm{~h}$. At ED12, the embryos were transferred to the stage of a SZX16 Wide Zoom Versatile 
Stereo Microscope (Olympus, Yokohama, Japan) and images were taken from inside the O-rings. The numbers of branches were calculated for five random images in each treatment and averaged.

\subsection{Cardiac Repair by (RADA)4-SDKP Hydrogel}

\subsubsection{Establishment of an Acute Myocardial Infarction (AMI) Rat Model}

All animal experiments were approved by the Royan Institute Ethics Committee in accordance with the NIH Guidelines for the Care and Use of Laboratory Animals (NIH Publication No. 85e23, revised 2010). Adult male Sprague Dawley rats (280-350 g) were anesthetized with intraperitoneal (IP) injections of $0.1 \mathrm{mg} / \mathrm{kg}$ medetomidine (Laboratorios Syva, AEM, Spain) and $75 \mathrm{mg} / \mathrm{kg}$ ketamine (Alfasan, Woerden The Netherlands). To maintain a deep level of anesthesia, intubation and mechanical ventilation (Harvard, state abbreviation, USA) with a mixture of room air, oxygen, and $1 \%$ isoflurane was performed. The chest area was shaved and a left thoracotomy was performed to expose the LV. The rat model of AMI was achieved by permanent ligation of the left anterior descending artery (LAD) with 6-0 monofilament silk suture material (Keyhan Teb, TehranIran). Validity of the AMI model was evaluated by color change to pale at the vicinity of the ligation and echocardiographic measurement one day after induction. Rats with $\mathrm{EF}<40 \%$ were selected as AMI models.

\subsubsection{Treatment Procedure}

Human bone marrow mesenchymal stem cells (BM-MSCs) at passages 3-5 were used as the cell source. The BM-MSCs were obtained from the Cell Bank (RSCB0178) of Royan Institute for Stem Cell Biology and Technology (Tehran, Iran) whose bone marrow was taken from a 34-year-old healthy male after written consent. The cells were cultured in $\alpha$-MEM with $20 \%$ inactivated FBS that contained L-glutamine, penicillin, and streptomycin. The AMI rats were randomly divided into four experimental groups: Vehicle, Cell, Gel, and Gel + Cell. The Vehicle group received an intramyocardial injection of PBS $(100 \mu \mathrm{L})$ at four sites of the infarct border zone. The Cell group received $2 \times 10^{6}$ human BM-MSCs in PBS $(100 \mu \mathrm{L})$. The Gel group received $0.25 \%$ SAP hydrogel $(100 \mu \mathrm{L})$ and the Gel + Cell group received $2 \times 10^{6}$ BM-MSCs encapsulated in $0.25 \%$ SAP hydrogel $(100 \mu \mathrm{L})$. Number of injected cells at Cell and Gel + Cell groups was chosen based upon previous reports [44]. After cell and/or hydrogel transplantation, each animal received an IP injection of $1 \mathrm{mg} / \mathrm{kg}$ atipamezole (Laboratorios Syva) and the animal was kept in an oxygen chamber on a heating stage until recovery. A prophylactic antibiotic ((Enrofloxacin, $15 \mathrm{mg} / \mathrm{kg}$, Rooyan Darou, Tehran, Iran) and analgesic (tramadol, $20 \mathrm{mg} / \mathrm{kg}$, Darou Pakhsh, Tehran, Iran) were injected IP for three days to prevent infection and pain.

\subsubsection{Echocardiography Measurements}

Functional evaluations of the hearts were performed by echocardiography using an ultrasound system (Mindray, city, state abbreviation, Hamburg, Germany) 1 day before the AMI induction (Pre), at day 1 after the AMI (Post1), and 4 weeks after the AMI (Post2). Rats were anesthetized by IP injections of $0.1 \mathrm{mg} / \mathrm{kg}$ medetomidine and $75 \mathrm{mg} / \mathrm{kg}$ ketamine, and their chests were shaved. A cardiologist, blinded to the treated groups, evaluated the cardiac function by ultrasound. Two-dimensional images were taken to illustrate functional echocardiography parameters. End-diastolic and systolic volumes were obtained to assess the LVEF. The changes in ejection fraction from day 1 to day $28(\triangle \mathrm{EF})$ were calculated and plotted. Fractional shortening (FS), the changes of fractional shortening from day 1 to day $28(\Delta \mathrm{FS})$, left ventricular inner diameter at diastole (LVIDd), and left ventricular inner diameter at systole (LVIDs) were extracted and depicted. The rats were euthanized at week 4 and their hearts were harvested for histological evaluations.

\subsubsection{Histological Studies}

On day 28, the hearts were excised and inundated in formalin $10 \%$ for 2 days. Following fixation, processing, and embedding in paraffin, the sections were cut into $5 \mu \mathrm{m}$ increments. After deparaffinization 
and hydration, Masson's trichrome (MT) staining was carried out on the heart sections. Then, percentage of fibrotic areas were determined by ImageJ software (version 1.47, acquired from http://imagej.nih.gov/ij/). The averaged infarct area was calculated from 12 slides in each animal, plotted, and compared between the experimental groups.

Sections from apex, middle, and base levels of each animal heart were chosen. Immunofluorescence staining of the deparaffinized and dehydrated sections was performed by subjecting the slides to antigen retrieval with Target Retrieval Solution (pH 9, Dako, S2368, Glostrup, Denmark) for 20 min. The sections were then permeabilized with $0.5 \%$ Triton X-100 at RT for $30 \mathrm{~min}$, blocked for $1 \mathrm{~h}$ at $37^{\circ} \mathrm{C}$, and incubated overnight with primary antibodies $\alpha$-SMA (Abcam: ab7817, Cambridge, Massachusetts, USA), CD68 (Sigma: 048982, Darmstadt, Germany), and STEM 121 (Clontech, Y40410, USA) at $4{ }^{\circ} \mathrm{C}$. Secondary antibody (anti-mouse IgG, Sigma, F9006) was applied at $37^{\circ} \mathrm{C}$ for $1 \mathrm{~h}$, counterstained with DAPI, and the sections were observed under a fluorescence microscope (Olympus; BX51). To quantify vascular density, the number of $\alpha-\mathrm{SMA}^{+}$structures at whole infarct zone of each section was assessed and the average number was plotted for each animal as number of $\alpha-\mathrm{SMA}^{+}$structures/field of infarct area [45]. Similarly, the numbers of $\mathrm{CD}^{+} 8^{+}$cells were counted in sections from apex, middle, and base to assess infiltration amount of macrophages at the site of infarction and expressed as number of CD68 ${ }^{+}$ cells/field of infarct area [46]. In order to track the transplanted MSCs, immunostaining of STEM121 as specific antibody against a cytoplasmic protein of human cells was performed.

\subsection{Statistical Analysis}

All data are presented as mean \pm standard deviation (SD). Statistical analysis was performed using GraphPad Prism 8.0.1 software (San Diego, CA, USA) by one-way analysis of variance (ANOVA) followed by the Tukey post-hoc test for comparisons between three or four groups and the Student's $t$-test for comparison between two groups. The survival experience in groups was analyzed by log-rank (Mantel-Cox) and Gehan-Breslow-Wilcoxon tests. $p<0.05$ was considered statistically significant.

\section{Results}

\subsection{Structure and Characterization of Self-Assembling Peptide (SAP) Hydrogel}

RADA16-I, as the core of the self-assembly, was decorated with the biologically active motif SDKP to create (RADA)4-SDKP as the precursor of a bioactive SAP hydrogel (Figure 1A). Regarding the HPLC assay that has been performed by DG Peptide company, a sharp single peak indicative of a highly pure product was observed (Figure 1B). The peptide solution was converted to hydrogel upon mixing with divalent calcium ions for less than $1 \mathrm{~min}$ (Figure 1C). Scanning electron microscopy confirmed the SAP hydrogel microstructure. The presence of a nanofiber-like pattern of the SAP could have been the result of binding and alignment of the peptide sequences following treatment with the positively charged ions (Figure 1D). We evaluated the rheological features of the hydrogel to investigate the changes in storage modulus $\left(G^{\prime}\right)$ and loss modulus $\left(G^{\prime \prime}\right)$ with shear frequency as the elastic and viscous terms of gel viscoelasticity, respectively. The prominent elastic behavior indicated by a higher $G^{\prime}$ value versus $G^{\prime \prime}$ and the plateau behavior of both $G^{\prime}$ and $G^{\prime \prime}$ confirmed the successful sol-gel transition (Figure 1E). The $\mathrm{G}^{\prime}$ and $\mathrm{G}^{\prime \prime}$ measurements indicated that a highly soft hydrogel was achieved, which guaranteed its injectability. To investigate the cell encapsulation potential of the SAP hydrogel, NMCMs were mixed with the (RADA)4-SDKP solution followed by calcium ion addition to enable the mixture to gel. The metabolic activity of the encapsulated NMCMs within the (RADA)4-SDKP hydrogel was assessed by MTS assay. The results showed no substantial change in cellular activity of the encapsulated cells compared to the cells cultured on tissue culture plate (TCP) as a control after $24 \mathrm{~h}, 48 \mathrm{~h}$, and $72 \mathrm{~h}$, which showed that the self-assembly process was safe for cell encapsulation and that the (RADA)4-SDKP hydrogel (0.25\% concentration) was biocompatible (Figure $1 F)$. 
A

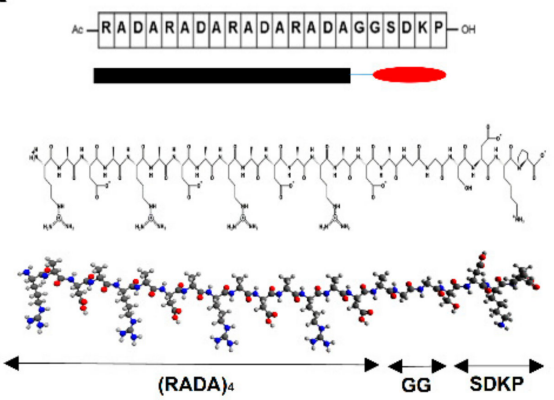

C
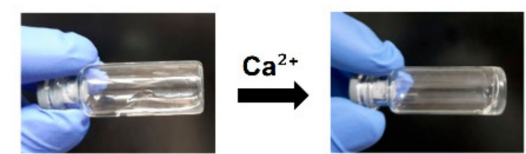

Sol

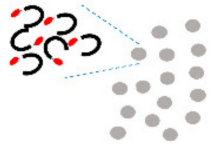

Gel

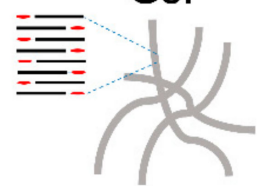

E

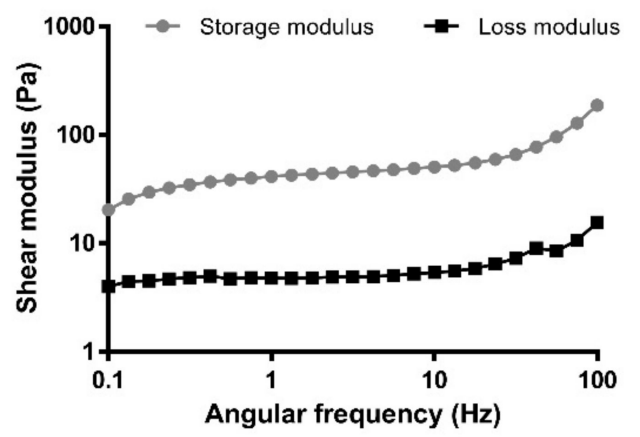

B

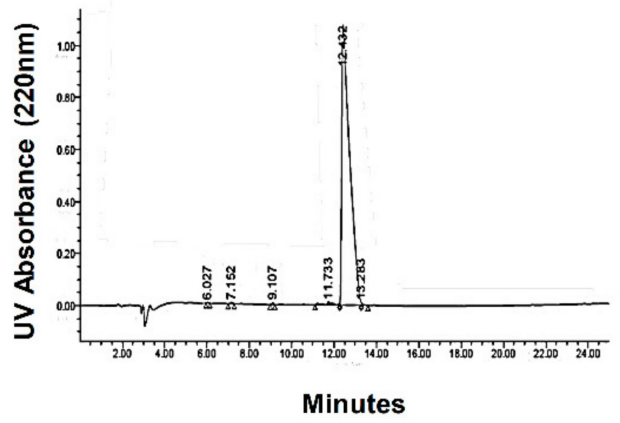

D
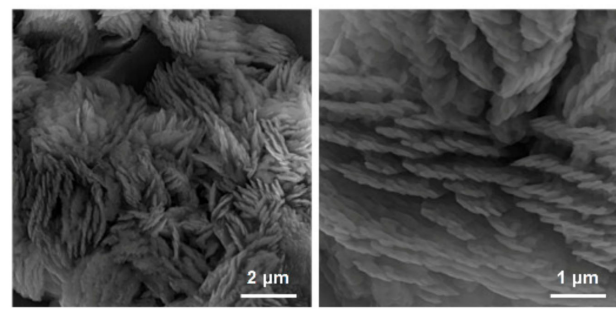

$\mathbf{F}$

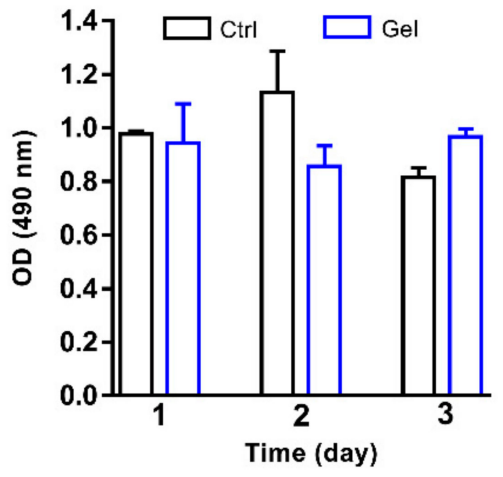

Figure 1. Structure and characterization of the self-assembling peptide (SAP) hydrogel. (A) Linear, chemical and three-dimensional structure of the (RADA) $)_{4}$-SDKP as a precursor of the SAP hydrogel. (B) HPLC graph related to (RADA) $)_{4}$-SDKP. (C) Visual illustration of gel formation by addition of $\mathrm{Ca}^{2+}$ to the $0.25 \%$ (RADA) $)_{4}$-SDKP solution. (D) Field emission scanning electron microscope (FESEM) images of $0.25 \%$ (RADA) $)_{4}$-SDKP hydrogel. (E) Viscoelasticity analysis of the $0.25 \%$ (RADA) $)_{4}$-SDKP hydrogel using shear rheometry. (F) MTS assay to test the cellular activity of neonatal mouse cardiomyocytes (NMCMs) after 1, 2, and 3 days of encapsulation in the (RADA) ${ }_{4}$-SDKP. MTS assay was performed in 3 biological replicates, each replicate included 4 repeats. Data are shown as mean \pm standard deviation.

\subsection{Angiogenic Potency of (RADA)4-SDKP}

The angiogenic potential of the (RADA)4-SDKP hydrogel was assessed by measurement of VEGF release and CAM assay. While VEGF release did not substantially differ between HUVECs plated on TCP $(338 \pm 6.9 \mathrm{pg} / \mathrm{mL})$ and those encapsulated in hydrogel $(444 \pm 92.2 \mathrm{pg} / \mathrm{mL})$ after $24 \mathrm{~h}(p>0.05)$, the five-day culture in (RADA)4-SDKP scaffold resulted in markedly increased VEGF release compared to the amount released by HUVECs cultured on TCP (455 \pm 79.9 vs. $150 \pm 19.8 \mathrm{pg} / \mathrm{mL}$, respectively, $p \leq 0.05$; Figure 2A).

CAM is a popular angiogenesis model that is a highly vascularized membrane located beneath an egg shell. Its location provides easy access for the application of diverse substances and monitoring vessel growth in response to these substances in real time. (RADA)4-SDKP treatment for $72 \mathrm{~h}$ substantially 
increased vascular density distal to the region of the application compared to the vehicle, which indicated its angiogenic potency $(9.33 \pm 1.5 \%$ vs. $5.33 \pm 0.5 \%, p \leq 0.05$; Figure $2 \mathrm{~B})$.
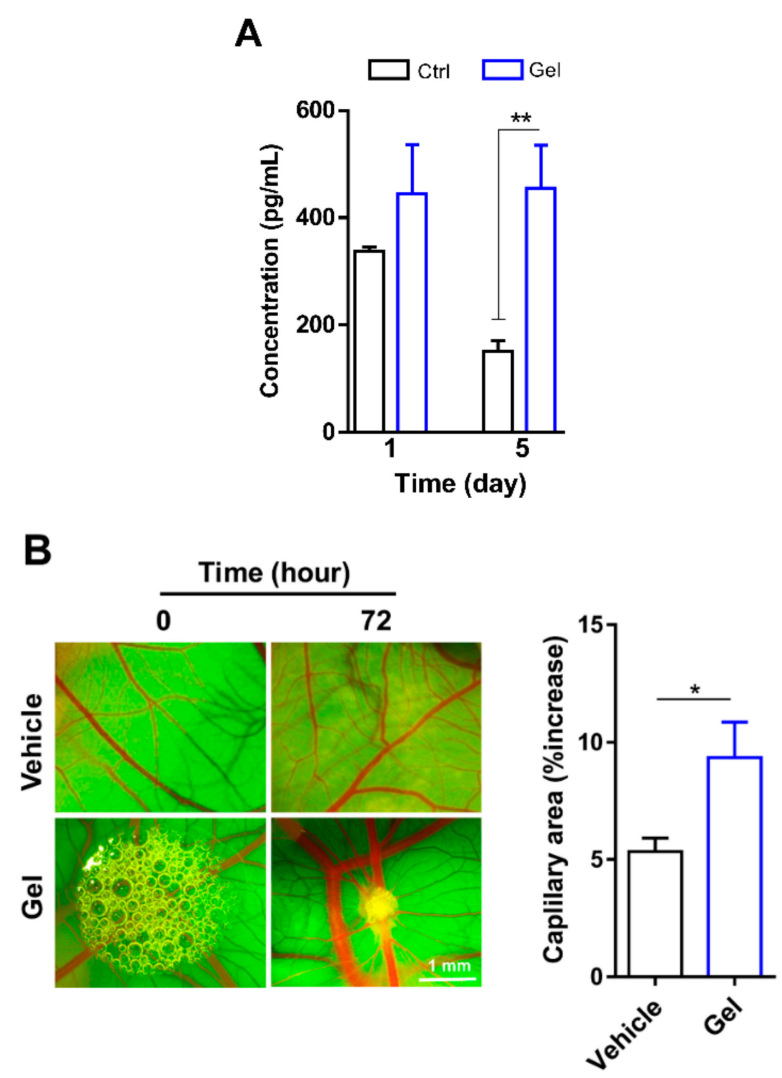

Figure 2. Angiogenic potential of (RADA) $)_{4}$ SDKP hydrogel. (A) Vascular endothelial growth factor (VEGF) release by human umbilical vein endothelial cells (HUVECs) cultured on either tissue culture plate as the control (Ctrl) or encapsulated in $0.25 \%$ (RADA) ${ }_{4}$-SDKP (Gel) after 1 and 5 days. (B) Representative images of the $0.25 \%(\mathrm{RADA})_{4}$-SDKP hydrogel placed on the chorioallantoic membranes (CAMs) at 0 and $72 \mathrm{~h}$ of incubation $(n=5, p \leq 0.05)$. Quantification of blood vessel area demonstrated that the $0.25 \%$ (RADA) $)_{4}$-SDKP hydrogel resulted in a statistically significant increase in response. Data are shown as mean \pm standard deviation $(n=3) .{ }^{*} p<0.05,{ }^{* *} p<0.01$.

\subsection{Cardiac Functional Restoration by (RADA)4-SDKP}

In an attempt to investigate the potential of the (RADA)4-SDKP hydrogel for cell delivery as treatment for MI, we transplanted BM-MSCs by an intramyocardial injection and using the (RADA)4-SDKP hydrogel as the carrier. Cardiac performance was assessed by echocardiography for all groups (Vehicle, Cell, Gel, and Gel + Cell) $24 \mathrm{~h}$ before MI (Baseline), 1 day after MI induction (Post 1) and 28 days after MI induction (Post 2) (Figure 3A). Animal survival did not significantly differ between all groups (Kaplan-Meier; Figure 3B). Echocardiographic measurements at baseline showed normal cardiac function in selected animals (EF $>70 \%, p>0.05)$. After LAD ligation, the color of the cardiac muscle became white from the point of the suture down to the apex, which indicated perfusion disturbances and hypoxia. The ventricular ejection fraction was drastically reduced one day after MI induction in all groups $(\mathrm{EF}<40 \%, p>0.05)$. Of note, animals with post $1 \mathrm{EF}>40 \%$ were excluded from the experiment.

Four weeks of treatment with the Gel and Gel+Cell restored the LVEF to a large extent, which was superior to that of the Cell and Vehicle groups as seen by the $\Delta$ EF of $20.33 \pm 2.94$ (Gel), $15.5 \pm 3.01$ (Gel + Cell), $5.8 \pm 2.16$ (Cell), and $-3.2 \pm 2.86$ (Vehicle) with a $p$-value of $<0.001$ (Figure 3C,D). 

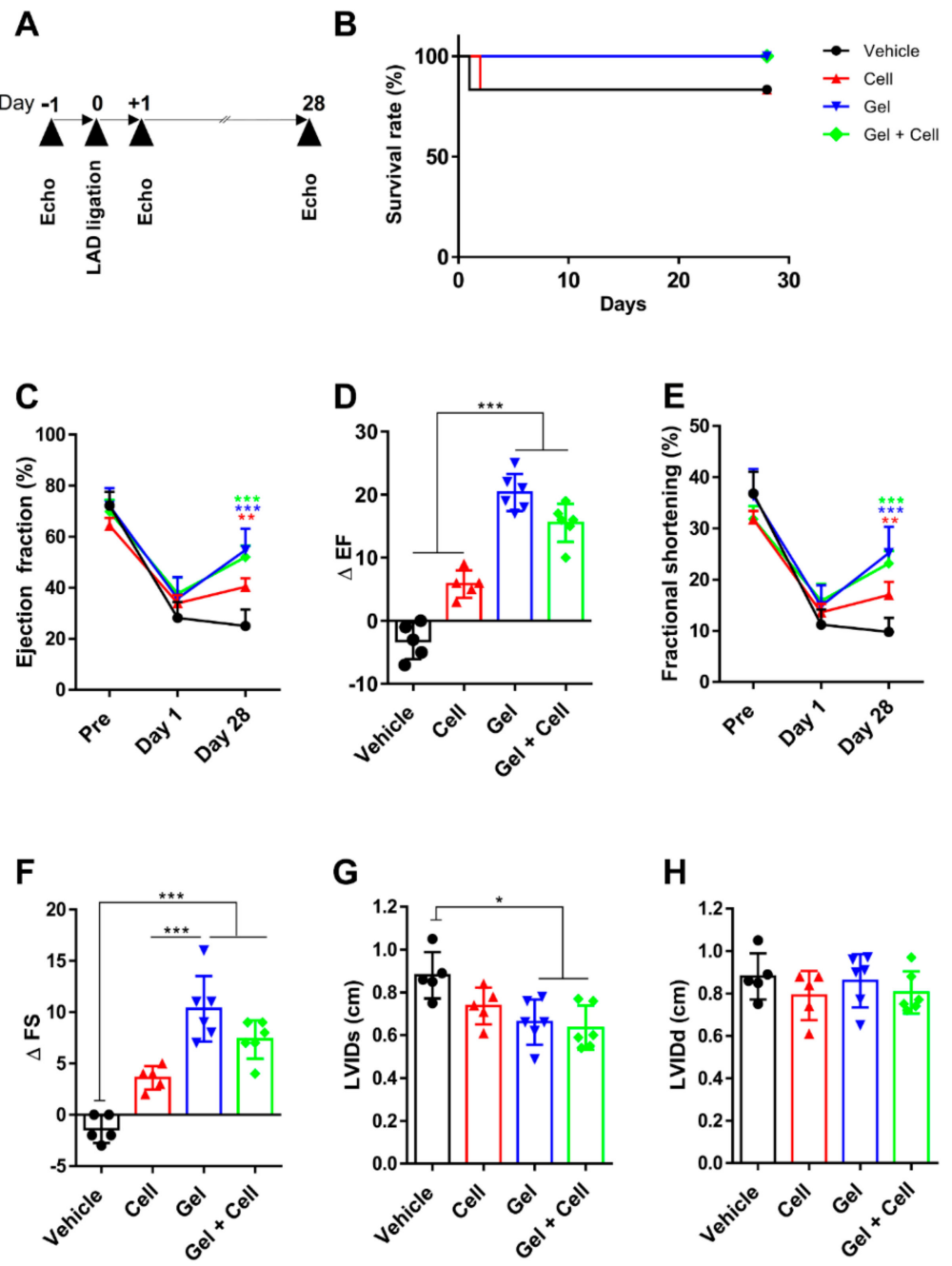

Figure 3. (RADA) $)_{4}$-SDKP hydrogel improved cardiac function after myocardial infarction (MI). (A) Schematic representation of the in vivo study design. The study animal groups included phosphate-buffered saline (PBS) as the Vehicle group, $2 \times 10^{6}$ bone marrow-derived mesenchymal stem cells (BM-MSCs) as the Cell group, $0.25 \%$ (RADA)4-SDKP (Gel), and $2 \times 10^{6}$ MSCs encapsulated within $0.25 \%$ (RADA) $)_{4}$-SDKP (Gel + Cell). We injected $100 \mu \mathrm{L}$ of the individual treatments into the peri-infarct region of the rats' hearts $15 \mathrm{~min}$ after induction of an acute myocardial infarction (MI). Next, echocardiographs were taken at 1 day before MI, 1 day after MI and 28 days after MI followed by histomorphometric evaluations of the rats' hearts. (B) Kaplan-Meier plot demonstrated increased survival in the Gel and Gel+Cell groups compared with the Cell and Vehicle groups. (C) Ejection fraction (EF) in all groups at pre-operation, and days 1 and 28 after MI. At day 28, EF was increased in all of the treated groups compared with the Vehicle group. (D) Variations in EF from day 1 to day 28 ( $\triangle \mathrm{EF}$ ) was higher in the Gel and Gel + Cell groups. (E) Fractional shortening (FS) in all groups at pre-operation, days 1 and 28 after myocardial infarction are illustrated. On day 28, FS was higher in all treated groups compared with Vehicle. (F) Variation of fractional shortening from day 28 to day $1(\Delta \mathrm{FS})$ was greater in Gel and Gel + Cell group. (G) Slight improvement was discernable in the parameter of the left ventricular inner diameter at systole (LVIDs) for the Gel and Gel + Cell groups compared with the Vehicle group. (H) Left ventricular inner diameter at diastole (LVIDd) did not differ significantly between groups. All data are presented as mean \pm standard deviation, $n \geq 5, * p<0.05 ; * * p<0.01$; ${ }^{* * *} p<0.005$.

Consistent with the EF findings, contractile function of the LV showed improvement in the Gel and Gel + Cell treatment groups compared to the Vehicle group, as shown by the $\Delta \mathrm{FS}$ of $10.33 \pm 2.02$ (Gel) and $7.33 \pm 1.86(\mathrm{Gel}+$ Cell), $p<0.001$ (Figure 3E,F). However, MSC transplantation did not markedly restore ventricular contractility ( $\triangle \mathrm{FS}$ : $3.6 \pm 1.1$ (Cell) vs. $-1 \pm 1.34$ (Vehicle); Figure 3E,F). The LVIDs and 
LVIDd, which provide valuable information on contractile function of the LV and are used as indexes of ventricular wall dilation progression, were analyzed in the treatment groups. There were substantially smaller LVIDs in the Gel and Gel + Cell groups compared to the Cell and Vehicle groups $(p<0.05$, Figure 3G). However, LVIDd did not differ among all treatment groups $(p>0.05$, Figure $3 \mathrm{H})$.

Quantification of the fibrotic area showed that functional improvement coincided with smaller scar formation in the infarct area of the rat hearts in the Gel $(17.83 \pm 4.9 \%)$ and Gel + Cell (12.5 \pm $7.59 \%)$ groups compared with the Cell $(41.5 \pm 2.88 \%)$ and Vehicle $(51.5 \pm 5.44 \%)$ groups $(p<0.001$, Figure $4 \mathrm{~A}, \mathrm{~B})$.

These data revealed substantial restoration of cardiac function when infarcted rat hearts were subjected to the Gel and Gel + Cell treatments. However, there appeared to be no marked differences between the Gel and Gel + Cell treatments with respect to their functional improvements, which highlighted the efficacy of the designated SAP hydrogel for cell-free cardiac functional restoration.

A

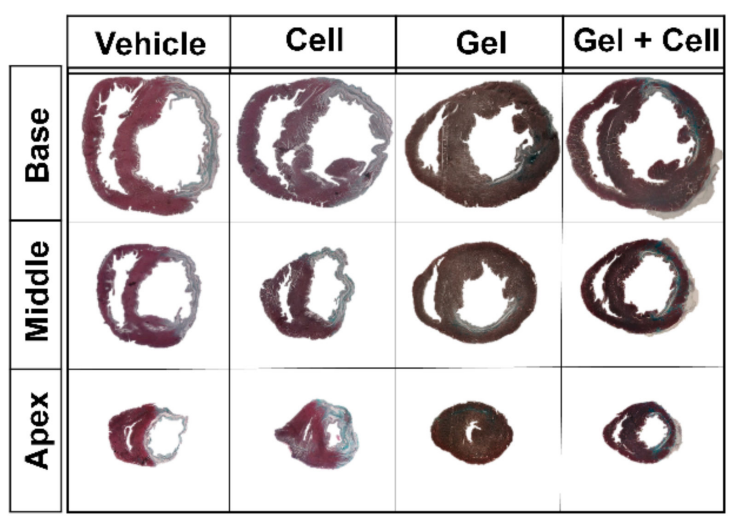

B

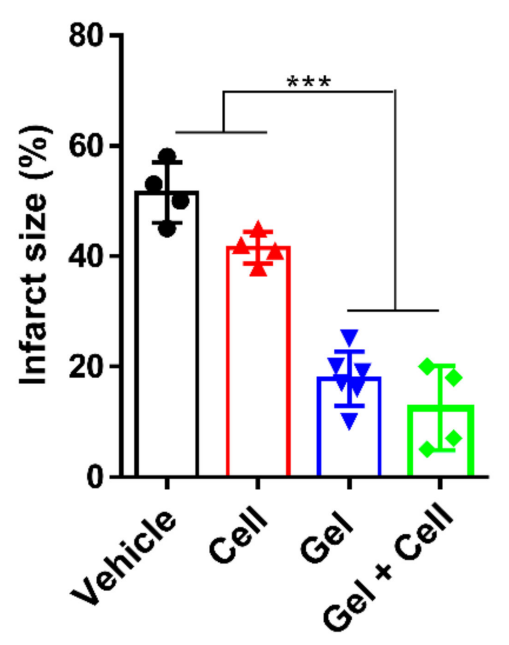

Figure 4. (RADA) $)_{4}$-SDKP hydrogel diminished scar size. (A) Representative images of Masson's trichrome (MT) stained heart sections at the apex, middle, and base areas for all groups. (B) At day 28, the infarct area (\% of left ventricle (LV)) was decreased in the Gel and Gel + Cell groups in comparison with the Cell and Vehicle groups. All data are presented as mean \pm standard deviation $(n \geq 4) \cdot{ }^{* * *} p<0.001$.

\subsection{Cardioprotective Mechanisms of (RADA)4-SDKP in Infarcted Rat Hearts}

(RADA)4-SDKP treatment could efficiently inhibit the failure in cardiac functional reserve after an MI, which we further investigated with respect to angiogenesis and inflammatory response in the infarcted heart. Presence of SAP hydrogel in echocardiography images of post1 was confirmed (Figure S1 and Supplementary Movie 1). However, it was absent in echocardiography images of post2 
(Figure S1) and all histological sections. Thus, we concluded that the hydrogel degraded completely and disappeared after four weeks. Immunostaining by $\alpha$-SMA showed a substantially larger number of vessels in the infarct area of the LV following treatment with both the Gel (19 \pm 3$)$ and Gel + Cell $(16 \pm 1)$ groups compared to the Vehicle group $(9 \pm 1, p<0.05$, Figure 5A). Consistent with in vitro and CAM assays, (RADA)4-SDKP hydrogel augmented vascularization, which might underlie cardiac functional restoration following the $\mathrm{MI}$ in the rats. We assessed the inflammatory response at the infarct area by CD68 immunostaining as a marker of macrophages. There were considerably fewer CD68-stained cells in the infarct areas of the hearts that received (RADA)4-SDKP hydrogel (20 \pm 4$)$ or Gel + Cell $(23 \pm 6)$ compared to the Cell $(40 \pm 9)$ or Vehicle $(52 \pm 5)$ groups $(p<0.05$, Figure $5 \mathrm{~B})$. This finding indicated the probability of controlling the inflammatory response by this modified SAP hydrogel, which was comparable with the anti-macrophage recruitment of MSCs in our experimental setting. In order to check for BM-MSC retention after transplantation, STEM121 immunostaining was performed to specifically identify human cells at the injection site. The results showed the presence of STEM121 ${ }^{+}$cells when BM-MSCs were delivered by the (RADA)4-SDKP hydrogel (Figure 6).
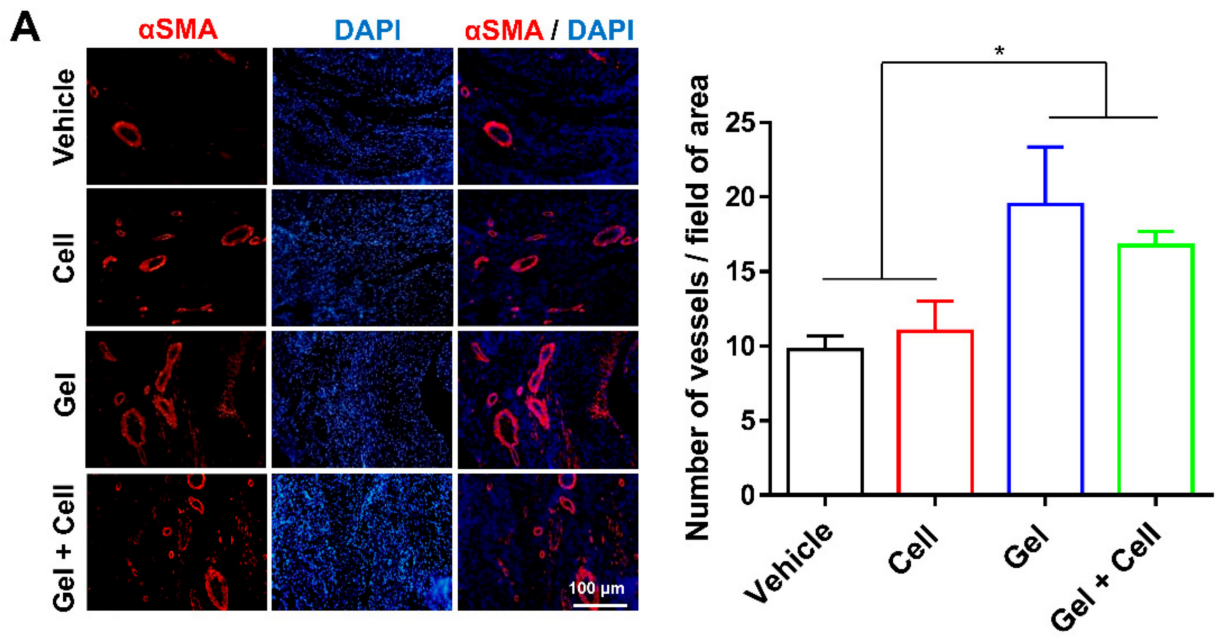

B
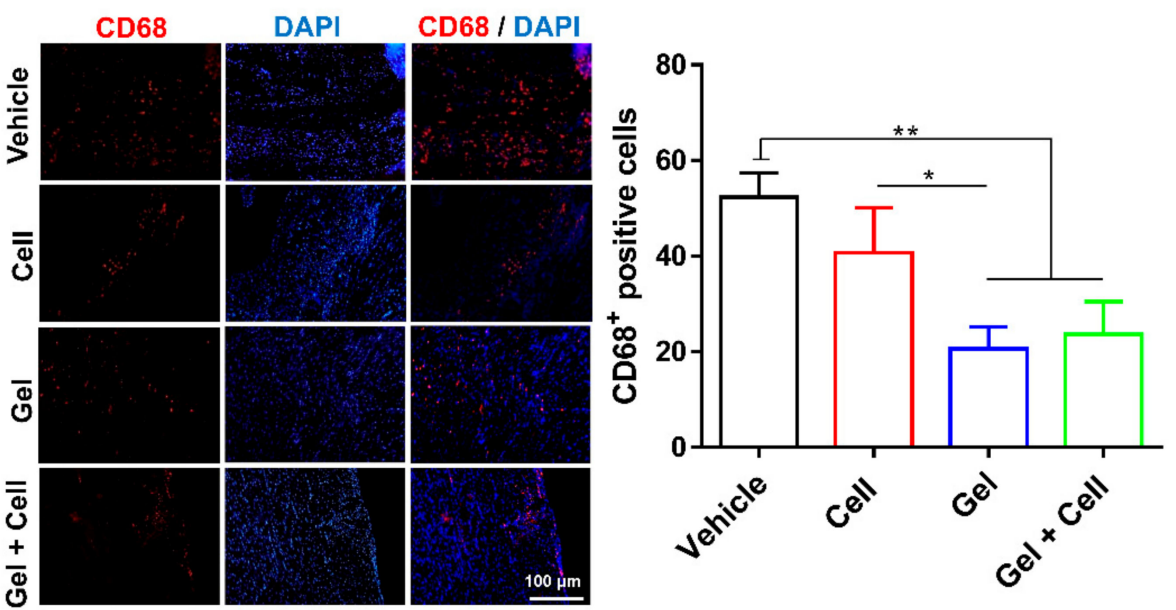

Figure 5. (RADA) $)_{4}$-SDKP hydrogel increased angiogenesis and reduced inflammation. (A) More vessels $\left(\alpha-\mathrm{SMA}^{+}\right.$cells $)$were detected in the Gel and Gel + Cell groups compared with the Vehicle group. (B) A lower number of $\mathrm{CD}^{+} 8^{+}$macrophages were observed in the Gel and Gel + Cell groups compared with the Cell and Vehicle groups. All data are presented as mean \pm standard deviation $(n \geq 3) .{ }^{*} p<0.05$; ** $p<0.01$. 

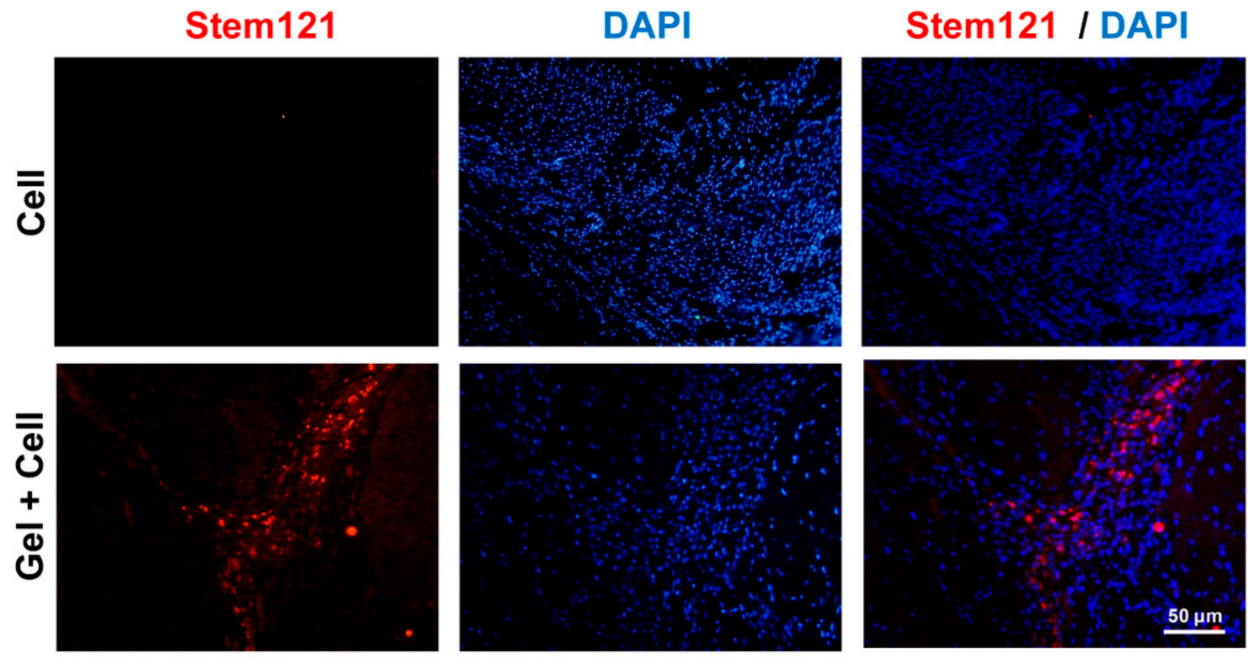

Figure 6. Cell retention after hydrogel-mediated delivery. At the fourth week, encapsulated mesenchymal stem cells (MSCs) that were injected into the myocardium were detected by immunostaining of STEM121 at the injection site.

\section{Discussion}

Adverse LV remodeling after MI directs cardiac tissue to a failing muscle, develops heart failure, and increases mortality $[47,48]$. Several strategies have been investigated for cardiac protection following MI, with over 6400 articles published since 1975; however, there is no ideal treatment available for this purpose [8].

Regenerative therapy for ischemic heart diseases, including cell-based therapy and cell-free approaches such as biomaterial scaffolds and delivery of bioactive molecules, is an active field of research that has launched several potential treatment strategies [49].

The current study examined a novel hypothesis that SDKP-conjugated SAP hydrogel would decelerate $\mathrm{LV}$ remodeling after AMI induction in rat hearts. This hydrogel could restore cardiac function. Furthermore, the (RADA)4-SDKP hydrogel had the capability to deliver and retain BM-MSCs at the site of the infarct. Thus, we designed a bioactive hydrogel that, in addition to an inherent cardioprotective effect, could efficiently deliver cells and improve their retention. However, the appropriate cell source should be further determined.

The SAP hydrogel has shown tremendous promise as a therapeutic biomaterial and addressed numerous indispensable requirements for myocardial therapy and regeneration [30]. RADA is a class of SAPs that can form supramolecular hydrogels upon mixing with the positively charged multivalent ions. The RADA-based hydrogels are biocompatible and biodegradable, mimic the nanofibrous structure of ECM, induce cell recruitment, and allow for sequence modification to render other bioactive functions $[50,51]$. These hydrogels have been used for the engineering of various tissues with low immunogenicity [52-54]. After injection of RADA16-II into the infarcted myocardium, the empty space of the hydrogel was cellularized by endothelial, smooth muscle, and cardiac cells within days, which showed the cell recruitment potential of the RADA-based hydrogels for endogenous regeneration of infarcted myocardium [30,55]. In order to improve cardiac function, cardioprotective and angiogenic cues such as IGF1 [56], PDGF [54], VEGF [57], FGF [58], Notch1 [16], and QHREDGS [59] have been integrated with the SAP hydrogels.

Angiogenesis is a vital mechanism that may alleviate heart dysfunction after MI. Hence, one of the key points in the regeneration of infarcted myocardium, either by resident progenitor cells or cell therapy, is sufficient angiogenesis in the target zone. Formation of new vessels and an adequate blood supply to the affected area reduces cardiomyocyte apoptosis and the level of fibrosis $[34,60,61]$. Some studies support the idea of SAP hydrogels modified with angiogenic motifs that promote cardiac repair. One proposed mechanism was an increase in vascular density and vessel diameter [57,61]. 
$\mathrm{N}$-acetyl-seryl-aspartyl-lysyl-proline (Ac-SDKP) is a tetrapeptide that has been well studied for improvement of the adverse effects of MI. Suggested mechanisms for cardiac healing of SDKP include enhancement of angiogenesis and reduction of fibrosis and inflammation [33-37]. Upon addition of calcium ions to the (RADA)4-SDKP solution, the amino acids reorganize in a nanofiber-like structure to form a supramolecular hydrogel without any chemical reaction. The safe conditions of the physical crosslinking could allow for encapsulation of the viable cells during gel formation. Moreover, the nanofibrous morphology might provide an ECM-mimetic microenvironment to support functionality of the cells [31].

From the various cell sources, MSCs appear to be promising for transplantation in MI [47,62]. Encapsulation of MSCs in SAP hydrogels has been proposed to overcome low engraftment of the cells and appeared to be beneficial in preclinical studies $[15,63]$. Consistent with previous studies, our SAP hydrogel was highly soft $\left(\mathrm{G}^{\prime} \sim 60 \mathrm{~Pa}\right)$, which might provide enough flexibility to not disrupt under heart beating [16]. In addition, the low density of the physical crosslinks could allow for easy injection of the gel due to its shear-thinning potential throughout the needle. In vitro and ex ovo assessments have shown the capability of the (RADA)4-SDKP hydrogel to induce angiogenic responses. Myocardial injection of the (RADA)4-SDKP hydrogel (Gel) at the infarcted area restored cardiac function after four weeks of follow-up. The higher probability of infarct area reduction, blood vessel density increment, and inflammatory response alleviation might be attributed to inherent properties of the SDKP motif, which is distributed in the entire structure of the hydrogel. However, this should be further investigated. Particularly, it is of great value to investigate the three phases of post-infarction inflammatory response [64] to address the time-dependent activation of macrophages. These results agreed with other studies that have used SAPs in a cell-free approach $[16,61,65]$. We also examined the potential of using the SAP hydrogel as a cell delivery vehicle. To this end, BM-MSCs were encapsulated within the (RADA)4-SDKP hydrogel during gel formation to make a cocktail with potential cardioprotective effect (Gel + Cell group). Of note, free injection of BM-MSCs did not show restoration of cardiac function compared with the vehicle group. These data were expected due to the probability of cell washout from contracting myocardium and poor retention. Furthermore, no trace of the gel was detectable in the histological sections of 28 days' post-treatment. This observation was in agreement with the echocardiography observations where the injected gel was clearly detectable on day 1 , whereas it disappeared on day 28 , suggesting complete degradation of the gel during the four-week experiment. Nevertheless, the transplanted BM-MSCs were detectable after 28 days in the infarct region when delivered by the SAP hydrogel as was confirmed by STEM121 expression, as a human cell marker.

We observed similar results on the evaluated cardiac parameters after both Gel and Gel + Cell treatments. Ichihara et al. combined SAPs and MSCs to improve engraftment via epicardial coating, which led to enhanced echocardiographic metrics of the infarcted hearts [15]. Thus, besides its inherent cardiac anti-remodeling effect following MI, (RADA)4-SDKP can be combined with an appropriate cell source to enhance the efficiency of cell therapy. In general, cell-free systems such as this modified self-assembling peptide could provide highly competitive approaches for regenerative therapy of MI.

\section{Conclusions}

Delivery of a $0.25 \%$ (RADA) $)_{4}$-SDKP hydrogel to the infarcted rat heart as a cell-free SAP-based scaffold resulted in improved cardiac function coupled with increased vessel formation and reduced fibrosis and inflammation. Intramyocardial injection of (RADA) ${ }_{4}$-SDKP hydrogel could be an effective acellular therapy for myocardial repair with the possibility for clinical translation.

Supplementary Materials: The following are available online at http://www.mdpi.com/2218-273X/10/2/205/s1, Figure S1: Presence assessment of SAP hydrogel at Post1 and Post2, Movie S1: Presence assessment of SAP hydrogel at Post1. 
Author Contributions: Conceptualization, S.F. and S.T.; Data curation, S.P. and M.-H.G.; Formal analysis, S.P. and M.-H.G.; Funding acquisition, H.B.; Investigation, S.F.; Methodology, S.R., M.B., S.Y., and E.M.; Project administration, H.B.; Supervision, M.S. and H.B.; Validation, S.P. and M.-H.G.; Writing-original draft, S.F.; Writing-review and editing, S.P., M.-H.G., and H.B. All authors have read and agreed to the published version of the manuscript.

Funding: This research was funded by Royan Institute grant number [96000198], Iran University of Medical Sciences grant number [96018730009] and the Iran National Science Foundation grant number [96001316].

Acknowledgments: This work was supported by grants from the Royan Institute and the Iran National Science Foundation (INSF, grant no. 96001316) to H.B and Iran University of Medical Sciences to M.S.

Conflicts of Interest: The authors declare no conflict of interest.

\section{References}

1. Go, A.S.; Mozaffarian, D.; Roger, V.L.; Benjamin, E.J.; Berry, J.D.; Borden, W.B.; Bravata, D.M.; Dai, S.; Ford, E.S.; Fox, C.S.; et al. Executive Summary: Heart Disease and Stroke Statistics-2013 Update: A Report From the American Heart Association. Circulation 2013, 127, 143-152. [CrossRef]

2. Anversa, P. Myocyte apoptosis and heart failure. Eur. Hear. J. 1998, 19, 359.

3. Aoyagi, T.; Matsui, T. The Cardiomyocyte as a Source of Cytokines in Cardiac Injury. J. Cell Sci. Ther. 2011, 2012. [CrossRef] [PubMed]

4. Amir, O.; Smith, R.; Nishikawa, A.; Gregoric, I.D.; Smart, F.W.J.T.H.I.J. Left ventricular free wall rupture in acute myocardial infarction: A case report and literature review. Tex. Heart Inst. J. 2005, 32, 424. [PubMed]

5. Frangogiannis, N.G. Regulation of the inflammatory response in cardiac repair. Circ. Res. 2012, 110, 159-173. [CrossRef] [PubMed]

6. Head, S.J.; Mack, M.J.; Holmes, D.R.; Mohr, F.W.; Morice, M.-C.; Serruys, P.W.; Kappetein, A.P. Incidence, predictors and outcomes of incomplete revascularization after percutaneous coronary intervention and coronary artery bypass grafting: A subgroup analysis of 3-year SYNTAX data. Eur. J. Cardio-Thorac. Surg. 2011, 41, 535-541. [CrossRef]

7. Sutton, M.G.S.J.; Sharpe, N. Left ventricular remodeling after myocardial infarction: Pathophysiology and therapy. Circulation 2000, 101, 2981-2988. [CrossRef]

8. Lefer, D.J.; Marbán, E. Is Cardioprotection Dead? Circulation 2017, 136, 98-109. [CrossRef]

9. Van Vliet, P.; Sluijter, J.P.; A Doevendans, P.; Goumans, M.-J. Isolation and expansion of resident cardiac progenitor cells. Expert Rev. Cardiovasc. Ther. 2007, 5, 33-43. [CrossRef]

10. Ward, M.R.; Abadeh, A.; Connelly, K.A. Concise Review: Rational Use of Mesenchymal Stem Cells in the Treatment of Ischemic Heart Disease. STEM CELLS Transl. Med. 2018, 7, 543-550. [CrossRef]

11. Bianconi, V.; Sahebkar, A.; Kovanen, P.; Bagaglia, F.; Ricciuti, B.; Calabrò, P.; Patti, G.; Pirro, M. Endothelial and cardiac progenitor cells for cardiovascular repair: A controversial paradigm in cell therapy. Pharmacol. Ther. 2018, 181, 156-168. [CrossRef] [PubMed]

12. Emmert, M.; Templin, C.J.P. Cardiac stem and progenitor cell therapy: Ready for the future? Praxis 2013, 102, 465-472. [CrossRef] [PubMed]

13. Kreke, M.; Smith, R.R.; Marbán, L.; Marbán, E. Cardiospheres and cardiosphere-derived cells as therapeutic agents following myocardial infarction. Expert Rev. Cardiovasc. Ther. 2012, 10, 1185-1194. [CrossRef] [PubMed]

14. Palojoki, E.; Saraste, A.; Eriksson, A.; Pulkki, K.; Kallajoki, M.; Voipio-Pulkki, L.-M.; Tikkanen, I. Cardiomyocyte apoptosis and ventricular remodeling after myocardial infarction in rats. Am. J. Physiol. Circ. Physiol. 2001, 280, H2726-H2731. [CrossRef] [PubMed]

15. Ichihara, Y.; Kaneko, M.; Yamahara, K.; Koulouroudias, M.; Sato, N.; Uppal, R.; Yamazaki, K.; Saito, S.; Suzuki, K.J.B. Self-assembling peptide hydrogel enables instant epicardial coating of the heart with mesenchymal stromal cells for the treatment of heart failure. Biomaterials 2018, 154, 12-23. [CrossRef]

16. Boopathy, A.V.; Martinez, M.D.; Smith, A.W.; Brown, M.E.; Garcia, A.J.; Davis, M.E. Intramyocardial Delivery of Notch Ligand-Containing Hydrogels Improves Cardiac Function and Angiogenesis Following Infarction. Tissue Eng. Part A 2015, 21, 2315-2322. [CrossRef]

17. Seliktar, D. Designing Cell-Compatible Hydrogels for Biomedical Applications. Science 2012, 336, 1124-1128. [CrossRef] 
18. Chen, C.W.; Wang, L.L.; Zaman, S.; Gordon, J.; Arisi, M.F.; Venkataraman, C.M.; Chung, J.J.; Hung, G.; Gaffey, A.C.; A Spruce, L.; et al. Sustained release of endothelial progenitor cell-derived extracellular vesicles from shear-thinning hydrogels improves angiogenesis and promotes function after myocardial infarction. Cardiovasc. Res. 2018, 114, 1029-1040. [CrossRef]

19. Carlini, A.S.; Gaetani, R.; Braden, R.L.; Luo, C.; Christman, K.L.; Gianneschi, N.C. Enzyme-responsive progelator cyclic peptides for minimally invasive delivery to the heart post-myocardial infarction. Nat. Commun. 2019, 10, 1735. [CrossRef]

20. Singelyn, J.M.; DeQuach, J.A.; Seif-Naraghi, S.B.; Littlefield, R.B.; Schup-Magoffin, P.J.; Christman, K.L.J.B. Naturally derived myocardial matrix as an injectable scaffold for cardiac tissue engineering. Biomaterials 2009, 30, 5409-5416. [CrossRef]

21. Dorsey, S.M.; McGarvey, J.R.; Wang, H.; Nikou, A.; Arama, L.; Koomalsingh, K.J.; Kondo, N.; Gorman, J.H.; Pilla, J.J.; Gorman, R.C.; et al. MRI evaluation of injectable hyaluronic acid-based hydrogel therapy to limit ventricular remodeling after myocardial infarction. Biomaterials 2015, 69, 65-75. [CrossRef] [PubMed]

22. Lee, A.S.; Inayathullah, M.; Lijkwan, M.A.; Zhao, X.; Sun, W.; Park, S.; Hong, W.X.; Parekh, M.B.; Malkovskiy, A.V.; Lau, E.; et al. Prolonged survival of transplanted stem cells after ischaemic injury via the slow release of pro-survival peptides from a collagen matrix. Nat. Biomed. Eng. 2018, 2, 104-113. [CrossRef] [PubMed]

23. Losi, P.; Briganti, E.; Magera, A.; Spiller, D.; Ristori, C.; Battolla, B.; Balderi, M.; Kull, S.; Balbarini, A.; Di Stefano, R.; et al. Tissue response to poly(ether)urethane-polydimethylsiloxane-fibrin composite scaffolds for controlled delivery of pro-angiogenic growth factors. Biomaterials 2010, 31, 5336-5344. [CrossRef] [PubMed]

24. Lee, K.Y.; Mooney, D.J. Hydrogels for Tissue Engineering. Chem. Rev. 2001, 101, 1869-1880. [CrossRef]

25. Bastings, M.M.C.; Koudstaal, S.; Kieltyka, R.E.; Nakano, Y.; Pape, A.C.H.; Feyen, D.A.M.; Van Slochteren, F.J.; Doevendans, P.A.; Sluijter, J.P.G.; Meijer, E.W.; et al. Drug Delivery: A Fast pH-Switchable and Self-Healing Supramolecular Hydrogel Carrier for Guided, Local Catheter Injection in the Infarcted Myocardium. Adv. Heal. Mater. 2014, 3, 69. [CrossRef]

26. Fujimoto, K.L.; Ma, Z.; Nelson, D.M.; Hashizume, R.; Guan, J.; Tobita, K.; Wagner, W.R.J.B. Synthesis, characterization and therapeutic efficacy of a biodegradable, thermoresponsive hydrogel designed for application in chronic infarcted myocardium. Biomaterials 2009, 30, 4357-4368. [CrossRef]

27. Panda, J.J.; Chauhan, V.S. Short peptide based self-assembled nanostructures: Implications in drug delivery and tissue engineering. Polym. Chem. 2014, 5, 4431-4449. [CrossRef]

28. Kumar, V.A.; Taylor, N.L.; Shi, S.; Wang, B.K.; Jalan, A.A.; Kang, M.K.; Wickremasinghe, N.C.; Hartgerink, J.D. Highly Angiogenic Peptide Nanofibers. ACS Nano 2015, 9, 860-868. [CrossRef]

29. Akiyama, N.; Yamamoto-Fukuda, T.; Takahashi, H.; Koji, T. In situ tissue engineering with synthetic self-assembling peptide nanofiber scaffolds, PuraMatrix, for mucosal regeneration in the rat middle-ear. Int. J. Nanomed. 2013, 8, 2629-2640. [CrossRef]

30. French, K.M.; Somasuntharam, I.; Davis, M.E. Self-assembling peptide-based delivery of therapeutics for myocardial infarction. Adv. Drug Deliv. Rev. 2016, 96, 40-53. [CrossRef]

31. Li, X.; Chen, Y.-Y.; Wang, X.-M.; Gao, K.; Gao, Y.-Z.; Cao, J.; Zhang, Z.-L.; Lei, J.; Jin, Z.-Y.; Wang, Y.-N. Image-guided stem cells with functionalized self-assembling peptide nanofibers for treatment of acute myocardial infarction in a mouse model. Am. J. Transl. Res. 2017, 9, 3723-3731. [PubMed]

32. Webber, M.J.; Han, X.; Prasanna Murthy, S.; Rajangam, K.; Stupp, S.I.; Lomasney, J.W.J.J.O.T.E.; Medicine, R. Capturing the stem cell paracrine effect using heparin-presenting nanofibres to treat cardiovascular diseases. J. Tissue Eng. Regen. Med. 2010, 4, 600-610. [CrossRef] [PubMed]

33. Cavasin, M.A.J.A.J.O.C.D. Therapeutic Potential of Thymosin- $\beta 4$ and its Derivative N-acetyl-seryl-aspartyllysyl-proline (Ac-SDKP) in Cardiac Healing After Infarction. Am. J. Cardiovasc. Drugs 2006, 6, 305-311. [CrossRef] [PubMed]

34. González, G.E.; Rhaleb, N.-E.; Nakagawa, P.; Liao, T.-D.; Liu, Y.; Leung, P.; Dai, X.; Yang, X.-P.; Carretero, O.A.J.C.s. $\mathrm{N}$-acetyl-seryl-aspartyl-lysyl-proline reduces cardiac collagen cross-linking and inflammation in angiotensin II-induced hypertensive rats. Clin. Sci. 2014, 126, 85-94. [CrossRef]

35. Gaudron, S.; Adeline, M.-T.; Potier, P.; Thierry, J. NAcSDKP Analogues Resistant to Angiotensin-Converting Enzyme. J. Med. Chem. 1997, 40, 3963-3968. [CrossRef] 
36. Yang, F.; Yang, X.-P.; Liu, Y.-H.; Xu, J.; Cingolani, O.; Rhaleb, N.-E.; Carretero, O.A.J.H. Ac-SDKP reverses inflammation and fibrosis in rats with heart failure after myocardial infarction. Hypertension 2004, 43, 229-236. [CrossRef]

37. Rossdeutsch, A.; Smart, N.; Riley, P.R. Thymosin $\beta 4$ and Ac-SDKP: Tools to mend a broken heart. J. Mol. Med. 2008, 86, 29-35. [CrossRef]

38. Semino, C.E. Self-assembling Peptides: From Bio-inspired Materials to Bone Regeneration. J. Dent. Res. 2008, 87, 606-616. [CrossRef]

39. Stupp, S.I. Self-assembly and biomaterials. Nano Letters 2010, 10, 4783-4786. [CrossRef]

40. Tavakol, S.; Saber, R.; Hoveizi, E.; Tavakol, B.; Aligholi, H.; Ai, J.; Rezayat, S.M.J.M.n. Self-assembling peptide nanofiber containing long motif of laminin induces neural differentiation, tubulin polymerization, and neurogenesis: In vitro, ex vivo, and in vivo studies. Mol. Neurobiol. 2016, 53, 5288-5299. [CrossRef]

41. Ott, H.C.; Matthiesen, T.S.; Goh, S.-K.; Black, L.D.; Kren, S.M.; I Netoff, T.; A Taylor, D. Perfusion-decellularized matrix: Using nature's platform to engineer a bioartificial heart. Nat. Med. 2008, 14, 213-221. [CrossRef] [PubMed]

42. Varzideh, F.; Pahlavan, S.; Ansari, H.; Halvaei, M.; Kostin, S.; Feiz, M.-S.; Latifi, H.; Aghdami, N.; Braun, T.; Baharvand, H. Human cardiomyocytes undergo enhanced maturation in embryonic stem cell-derived organoid transplants. Biomaterials 2019, 192, 537-550. [CrossRef] [PubMed]

43. Yu, Y.; Chen, R.; Sun, Y.; Pan, Y.; Tang, W.; Zhang, S.; Cao, L.; Yuan, Y.; Wang, J.; Liu, C. Manipulation of VEGF-induced angiogenesis by 2-N, 6-O-sulfated chitosan. Acta Biomater. 2018, 71, 510-521. [CrossRef] [PubMed]

44. Bian, S.; Zhang, L.; Duan, L.; Wang, X.; Min, Y.; Yu, H.J.J.o.m.m. Extracellular vesicles derived from human bone marrow mesenchymal stem cells promote angiogenesis in a rat myocardial infarction model. J. Mol. Med. 2014, 92, 387-397. [CrossRef] [PubMed]

45. Vahdat, S.; Mousavi, S.A.; Omrani, G.; Gholampour, M.; Sotoodehnejadnematalahi, F.; Ghazizadeh, Z.; Gharechahi, J.; Baharvand, H.; Salekdeh, G.H.; Aghdami, N. Cellular and Molecular Characterization of Human Cardiac Stem Cells Reveals Key Features Essential for Their Function and Safety. Stem Cells Dev. 2015, 24, 1390-1404. [CrossRef]

46. Chen, C.-H.; Hsu, S.-Y.; Chiu, C.-C.; Leu, S. MicroRNA-21 Mediates the Protective Effect of CardiomyocyteDerived Conditioned Medium on Ameliorating Myocardial Infarction in Rats. Cells 2019, 8, 935. [CrossRef]

47. St John Sutton, M.; Pfeffer, M.A.; Plappert, T.; Rouleau, J.-L.; Moyé, L.A.; Dagenais, G.R.; Lamas, G.A.; Klein, M.; Sussex, B.; Goldman, S.J.C. Quantitative two-dimensional echocardiographic measurements are major predictors of adverse cardiovascular events after acute myocardial infarction. The protective effects of captopril. Circulation 1994, 89, 68-75. [CrossRef]

48. Pfeffer, M.A.; Braunwald, E.J.C. Ventricular remodeling after myocardial infarction. Experimental observations and clinical implications. Circulation 1990, 81, 1161-1172. [CrossRef]

49. Hastings, C.L.; Roche, E.T.; Ruiz-Hernández, E.; Schenke-Layland, K.; Walsh, C.J.; Duffy, G.P. Drug and cell delivery for cardiac regeneration. Adv. Drug Deliv. Rev. 2015, 84, 85-106. [CrossRef]

50. Yuan, X.; He, B.; Lv, Z.; Luo, S. Fabrication of self-assembling peptide nanofiber hydrogels for myocardial repair. RSC Adv. 2014, 4, 53801-53811. [CrossRef]

51. Ravichandran, R.; Venugopal, J.R.; Sundarrajan, S.; Mukherjee, S.; Ramakrishna, S. Minimally invasive cell-seeded biomaterial systems for injectable/epicardial implantation in ischemic heart disease. Int. J. Nanomed. 2012, 7, 5969-5994. [CrossRef] [PubMed]

52. Holmes, T.C.; De Lacalle, S.; Su, X.; Liu, G.; Rich, A.; Zhang, S. Extensive neurite outgrowth and active synapse formation on self-assembling peptide scaffolds. Proc. Natl. Acad. Sci. 2000, 97, 6728-6733. [CrossRef] [PubMed]

53. Davis, M.E.; Motion, J.M.; Narmoneva, D.A.; Takahashi, T.; Hakuno, D.; Kamm, R.D.; Zhang, S.; Lee, R.T. Injectable self-assembling peptide nanofibers create intramyocardial microenvironments for endothelial cells. Circulation 2005, 111, 442-450. [CrossRef] [PubMed]

54. Hsieh, P.C.; Davis, M.E.; Gannon, J.; MacGillivray, C.; Lee, R.T.J.T.J.O.C.I. Controlled delivery of PDGF-BB for myocardial protection using injectable self-assembling peptide nanofibers. J. Clin. Investig. 2006, 116, 237-248. [CrossRef] 
55. Singelyn, J.M.; Sundaramurthy, P.; Johnson, T.D.; Schup-Magoffin, P.J.; Hu, D.P.; Faulk, D.M.; Wang, J.; Mayle, K.M.; Bartels, K.; Salvatore, M.J.J.O.T.A.C.O.C. Catheter-deliverable hydrogel derived from decellularized ventricular extracellular matrix increases endogenous cardiomyocytes and preserves cardiac function post-myocardial infarction. J. Am. Coll. Cardiol. 2012, 59, 751-763. [CrossRef]

56. Davis, M.E.; Hsieh, P.C.H.; Takahashi, T.; Song, Q.; Zhang, S.; Kamm, R.D.; Grodzinsky, A.J.; Anversa, P.; Lee, R.T. Local myocardial insulin-like growth factor 1 (IGF-1) delivery with biotinylated peptide nanofibers improves cell therapy for myocardial infarction. Proc. Natl. Acad. Sci. USA 2006, 103, 8155-8160. [CrossRef]

57. Lin, Y.-D.; Luo, C.-Y.; Hu, Y.-N.; Yeh, M.-L.; Hsueh, Y.-C.; Chang, M.-Y.; Tsai, D.-C.; Wang, J.-N.; Tang, M.-J.; Wei, E.I.H.; et al. Instructive Nanofiber Scaffolds with VEGF Create a Microenvironment for Arteriogenesis and Cardiac Repair. Sci. Transl. Med. 2012, 4, 146ra109. [CrossRef]

58. Kim, J.H.; Jung, Y.; Kim, S.-H.; Sun, K.; Choi, J.; Kim, H.C.; Park, Y.; Kim, S.H. The enhancement of mature vessel formation and cardiac function in infarcted hearts using dual growth factor delivery with self-assembling peptides. Biomaterials 2011, 32, 6080-6088. [CrossRef]

59. Cai, H.; Wu, F.-Y.; Wang, Q.-L.; Xu, P.; Mou, F.-F.; Shao, S.-J.; Luo, Z.-R.; Zhu, J.; Xuan, S.-S.; Lu, R.; et al. Self-assembling peptide modified with QHREDGS as a novel delivery system for mesenchymal stem cell transplantation after myocardial infarction. FASEB J. 2019, 33, 8306-8320. [CrossRef]

60. Laflamme, M.A.; Zbinden, S.; Epstein, S.E.; Murry, C.E. Cell-Based Therapy for Myocardial Ischemia and Infarction: Pathophysiological Mechanisms. Annu. Rev. Pathol. Mech. Dis. 2007, 2, 307-339. [CrossRef]

61. Rufaihah, A.J.; Yasa, I.C.; Ramanujam, V.S.; Arularasu, S.C.; Kofidis, T.; Guler, M.O.; Tekinay, A.B. Angiogenic peptide nanofibers repair cardiac tissue defect after myocardial infarction. Acta Biomater. 2017, 58, $102-112$. [CrossRef] [PubMed]

62. E Hatzistergos, K.; Quevedo, H.; Oskouei, B.N.; Hu, Q.; Feigenbaum, G.S.; Margitich, I.S.; Mazhari, R.; Boyle, A.J.; Zambrano, J.P.; Rodriguez, J.E.; et al. Bone marrow mesenchymal stem cells stimulate cardiac stem cell proliferation and differentiation. Circ. Res. 2010, 107, 913-922. [CrossRef] [PubMed]

63. Gao, X.-R.; Xu, H.-J.; Wang, L.-F.; Liu, C.-B.; Yu, F. Mesenchymal stem cell transplantation carried in SVVYGLR modified self-assembling peptide promoted cardiac repair and angiogenesis after myocardial infarction. Biochem. Biophys. Res. Commun. 2017, 491, 112-118. [CrossRef] [PubMed]

64. Weinberger, T.; Schulz, C. Myocardial infarction: A critical role of macrophages in cardiac remodeling. Front. Physiol. 2015, 6, 107. [CrossRef] [PubMed]

65. Puig-Sanvicens, V.A.C.; Semino, C.E. Self-assembling peptide scaffolds as innovative platforms for drug and cell delivery systems in cardiac regeneration. Drug Deliv. Transl. Res. 2013, 3, 330-335. [CrossRef] [PubMed] 